\title{
Legal Reporting in Forensic Odontology
}

Manas Bajpai* and Nilesh Pardhe

Department of Oral and Maxillofacial Pathology, NIMS Dental College, Jaipur, India

*Corresponding author: Dr Manas Bajpai (M.D.S) Assistant Professor, Department of Oral and Maxillofacial Pathology, NIMS Dental College, Jaipur, India, Tel: 8302382133; E-mail: dr.manasbajpai@gmail.com

Received date: May 27, 2016, Accepted date: June 14, 2016, Published date: June 21, 2016

Copyright: (c) 2016 Bajpai M, et al. This is an open-access article distributed under the terms of the Creative Commons Attribution License, which permits unrestricted use, distribution, and reproduction in any medium, provided the original author and source are credited.

\section{Abstract \\ Writing an ideal Forensic odontology report is a blend of arts and science and sometimes it is challenging to write an ideal report. This article focuses on writing an ideal legal report.}

Keywords: Forensic odontology; Reporting; Legal report writing

\section{Introduction}

Examination of teeth in many ways forms a unique part of human body as they are most durable and resilient part of the skeleton [1]. The science dealing with establishing identity of a person by teeth is popularly known as Forensic Odontology or Forensic Dentistry. Dental professionals have a major role to play in keeping accurate dental records and providing all necessary information so that legal authorities may recognize mal practice, negligence, fraud or abuse, and identity of unknown individuals [2]. Apart from the documentation provided by the International Organization for Forensic Odontostomatology, [3] there is a paucity of literature available pertaining to the guidelines of an ideal and legal forensic odontology reporting. This limitation of the literature prompted the author to offer some more elaboration to the current guidelines, which can be easily adopted by forensic odontologists (Table 1-4).

\section{Report Writing}

\begin{tabular}{l} 
The Basic Requisites \\
\hline The report should fulfil the national guidelines comply with national laws \\
\hline The report should be written in a systemic way and it can be understandable by the lay person. \\
\hline The report must explain the cause of death (trauma or violence) on the basis of orodental findings. \\
If possible the raw data or the worksheet should be provided (documenting the different stages of the investigations) by the forensic odontologist along with the report.
\end{tabular}

Table 1: Basic requisite.

\section{The Requisition}

The request for casework should be in writing; however verbal requests can be considered but should be followed by a written request.

The request should contain all the information pertaining to the case and the questions to be answered.

Table 2: Requisition.

\begin{tabular}{|l|}
\hline The Report \\
\hline Before post - mortem \\
\hline Should be on official paper. \\
\hline Should be given all the basic information ( Forensic odontologist's name, Institution, address, email ) \\
\hline Obtain informed consent to the examination or alternatively view (and retain a copy of) a court order. \\
\hline Date and place of examination \\
\hline The date and detailing of the body, when it was found. \\
\hline
\end{tabular}




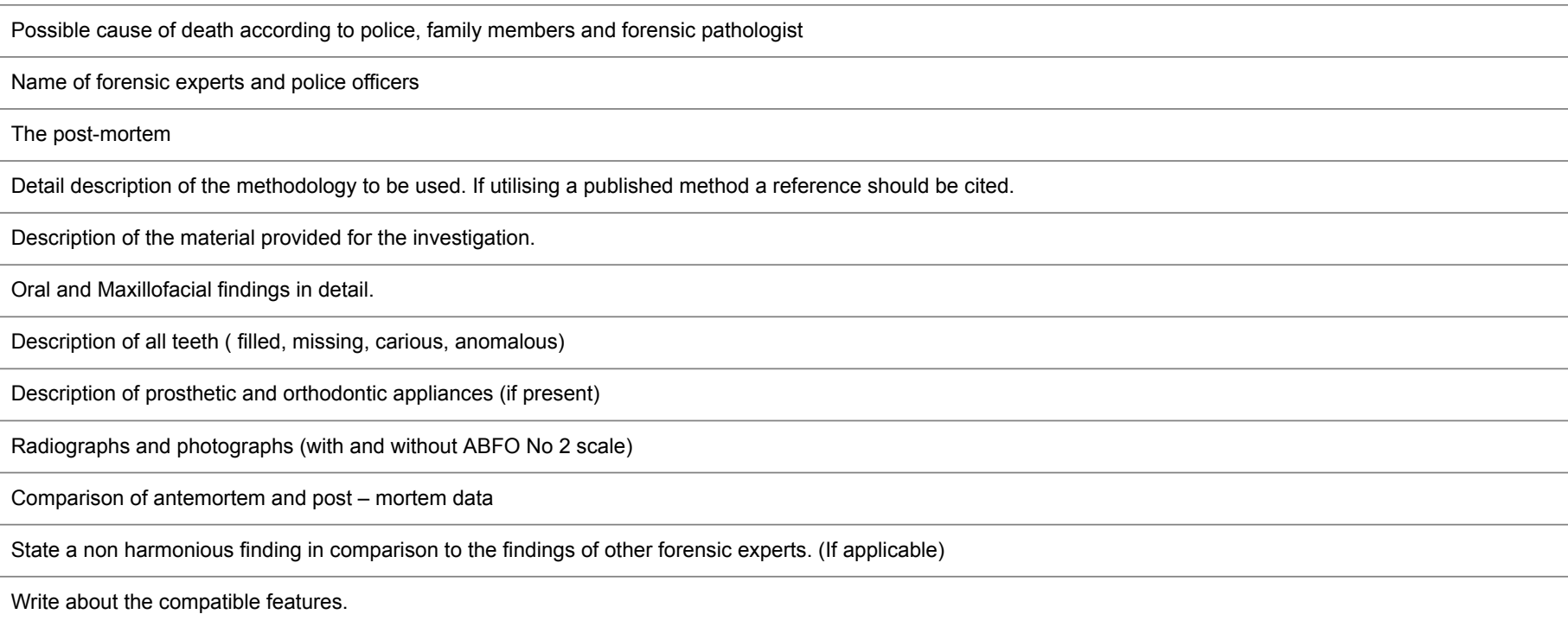

Table 3: Report.

\section{Drawing a conclusion}

A conclusion must be clear and descriptive and should not lead to misunderstanding.

State the comparative analysis of ante and post - mortem data.

State negative findings if relevant.

Give results from the calculations carried out for age and sex determination.

Discuss the interpretation of findings and results.

Try to address all the questions of requisition.

Discuss the limitations of the methods used.

State conclusions outside the request only if of great importance.

Finally, a report should be submitted to the relevant authority with the signature of the forensic odontologist accompanied by date, place, qualification and the statement that, the work and interpretation was done by best of his/her ability. The agreement of three forensic odontologists on the conclusion is required.

Table 4: Conclusion.

\section{References}

1. Bajpai M, Pardhe N, Agarwal M, Agrawal S (2015) A Comparative Evaluation of Gustafson's Formula and New Formula for Age Estimation in India--A Forensic Study. Prague Med Rep 116: 203-209.
2. http://www.iofos.eu/Quality-Ass/Report-IOFOS

3. Parikh CK (1990) Identification in Mass Disasters: CBS Publishers and Distribution. (5th edition), Parikh Text Book of Medical Jurisprudence and Toxicology, Bombay. 